Casos Clínicos

Arch. Esp. Urol. 2010; 63 (2): 147-150

\section{RECIDIVA TARDIAA DE UN CARCINOMA DE CÉLULAS RENALES. METÁSTASIS MAXILAR DERECHA 17 AÑOS DESPUÉS DE LA PRIMERA CIRUGÍA}

\author{
Miguel Álvarez-Múgica, Verónica Bulnes Vázquez, \\ Antonio Jalón Monzón, Alberto Gil, Laura Rodríguez \\ Robles y Oscar Miranda Aranzubía.
}

Servicio de Urología 1. Hospital Universitario Central de Asturias. Asturias. España.

Resumen.- OBJETIVOS: Presentar un nuevo caso de recidiva tardía de un carcinoma de células renales.

MÉTODOS: Los carcinomas renales suponen el 3\% de todos los tumores en el adulto. Los lugares más frecuentes de afectación metastático son el pulmón (76\%), ganglios linfáticos regionales (66\%), hueso (42\%) e hígado (4 1\%), y además, es la tercera neoplasia infraclavicular en frecuencia en metastatizar en cabeza y cuello.

\section{CORRESPONDENCIA}

Miguel Álvarez-Múgica

Servicio de Urología 1

Hospital Universitario Central de Asturias

Celestino Villamil, s/n

33006 Oviedo. Asturias. (España)

malvarezmug@gmail.com

Aceptado para publicar: 23 de julio 2009
RESULTADOS: Varón de 73 años que consulta por episodio de epistaxis de 1 semana de evolución. El paciente había sido sometido a una nefrectomía izquierda por una masa de $8,5 \mathrm{~cm}$ en polo superior renal 17 años antes. El informe anatomo patológico fue de carcinoma renal de células claras. No se evidenciaron metástasis en los estudios de extensión previos a la cirugía (Estadio I, pT2NOMO). En el nuevo ingreso se realizó un escaner que mostró una masa en la cavidad nasal derecha que invadía en el seno etmoidal y la órbita derecha. Se llevó a cabo una exploración bajo anestesia con toma de biopsia confirmando la histología de carcinoma renal de células claras.

CONCLUSIONES: La historia natural del cáncer renal es muy variable, pudiendo aparecer metástasis décadas después de la nefrectomía inicial, si bien sólo el 1\% de estos pacientes presentan metástasis confinadas solamente a la cabeza y cuello. El carcinoma de células renales debe ser considerado en el diagnóstico diferencial de cualquier masa en cabeza y cuello.

Palabras clave: Carcinoma de células renales. Metástasis maxilar. Epístaxis.

Summary.- OBJECTIVES: To report a new case of late renal cell carcinoma recurrence.

METHODS: Renal cell carcinoma represents approximately $3 \%$ of all adult malignancies. The most frequent metastatic sites are lung (76\%), regional lymph nodes (66\%), bone $(42 \%)$, and liver (41\%), and it is the third most common infraclavicular neoplasm to metastasize to head and neck.

RESULTS: 73 year-old man with a 7 week history of recurrent epistaxis. He underwent left nephrectomy 17 years before due to a renal mass of $8.5 \mathrm{~cm}$ in the upper pole of the left kidney. The histological diagnosis of the referred mass was clear cell carcinoma. No metastatic lesion was found at that time (Stage I, pT2NOMO). CT scan showed a mass in the right nasal cavity, invading the right ethmoidal sinus and the right orbit. Examination under general anaesthesia and biopsy was performed revealing metastasis of a renal cell carcinoma.

CONCLUSIONS: The natural history of renal cell carcinoma is highly variable, metastases may present decades after the removal of the primary disease, however, only $1 \%$ of patients with renal cell carcinoma have metastases confined only to the head and neck, and solitary cervical metastatic mass is rare. Moreover, renal cell carcinoma should be considered in the differential diagnosis of any growing lesion in the head and neck.

Keywords: Renal cell carcinoma. Maxilar metastases. Epistaxis. 


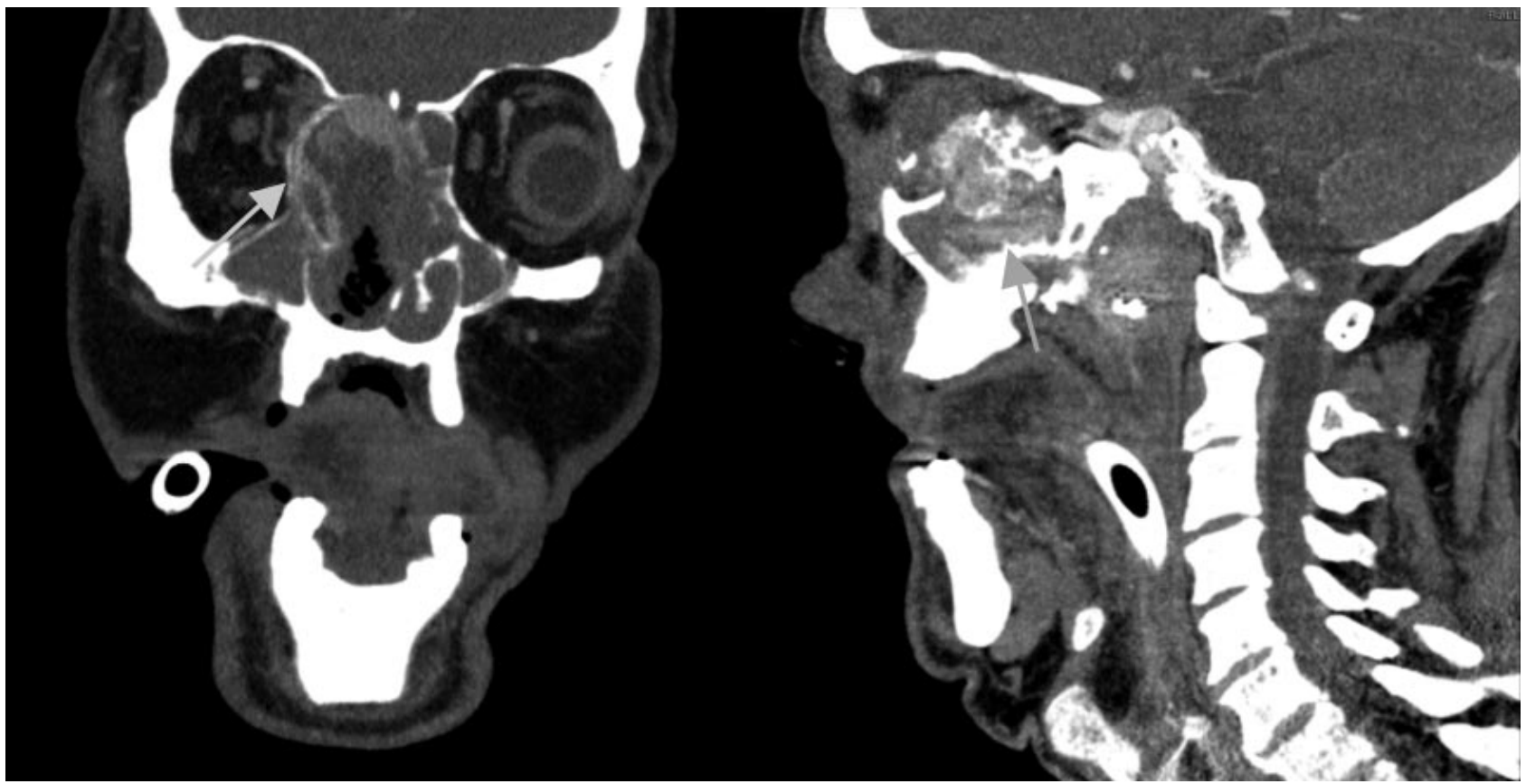

FIGURA 1. TC. Masa ocupando la cavidad nasal derecha, invadiendo el seno etmoidal derecho y la órbita derecha.

\section{INTRODUCCIÓN}

El carcinoma de células renales representa el 3\% de todas las neoplasias del adulto. El lugar más frecuente de metástasis es el hueso y el pulmón, si bien han sido descritas metástasis en cualquier órgano y lugar del organismo (1). Es la tercera causa más frecuente de neoplasia infraclavicular que metastatiza en cabeza y cuello, tras el primario de pulmón y de mama. Describimos un caso de masa solitaria en el maxilar derecho de origen renal, 17 años tras la cirugía renal por carcinoma renal.

\section{CASO CLÍNICO}

Se trata de un varón de 73 años remitido al servicio de otorrinolaringología por episodio de epístasis recurrente de 1 semana de evolución. Como antecedentes, tan sólo reseñar que había sido sometido a nefrectomía izquierda, 17 años antes debido a una masa renal de 8,5 $\mathrm{cm}$ en el polo superior del riñón izquierdo. El informe histológico fue de carcinoma de células claras. En los estudios de extensión en ese momento no se detectaron ninguna lesión metastática en ese momento.

La exploración física mostró un intenso sangrado a través del orificio nasal derecho asociado a proptosis del globo ocular derecho. Se realizó un escáner, que mostró una masa en la cavidad nasal derecha con afectación del seno etmoidal derecho y la órbita derecha (Figura 1). Se practicó una exploración bajo anestesia con toma de biopsia confirmando el origen de carcinoma de células renales de la masa. El estudio angiográfico demostró una gran neovascularización muy marcada en la cavidad nasal derecha y en el seno etmoidal derecho que involucraba a la arteria maxilar interna derecha, así como a la arteria oftálmica derecha y a ramas de la arteria etmoidal (Figura 2). Se efectuó una embolización de la arteria maxilar interna derecha (Figura 3), sin conseguir un control efectivo del sangrado. El paciente falleció días después por shock hipovolémico.

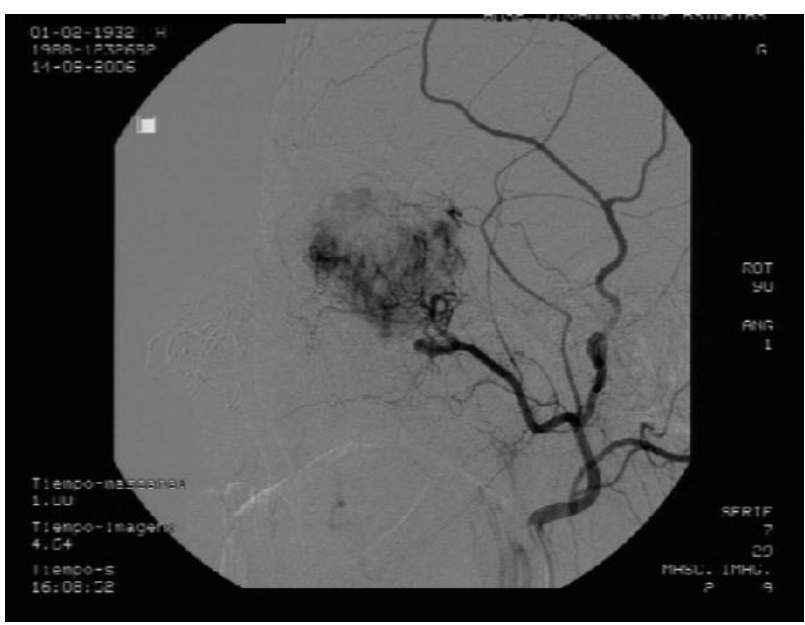

FIGURA 2. Arteriografía. Gran neovascularización más marcada en la cavidad nasal derecha y en el seno etmoidal derecho, afectando a la arteria maxilar interna derecha, así como a la arteria oftálmica derecha y a ramas de la arteria etmoidal. 

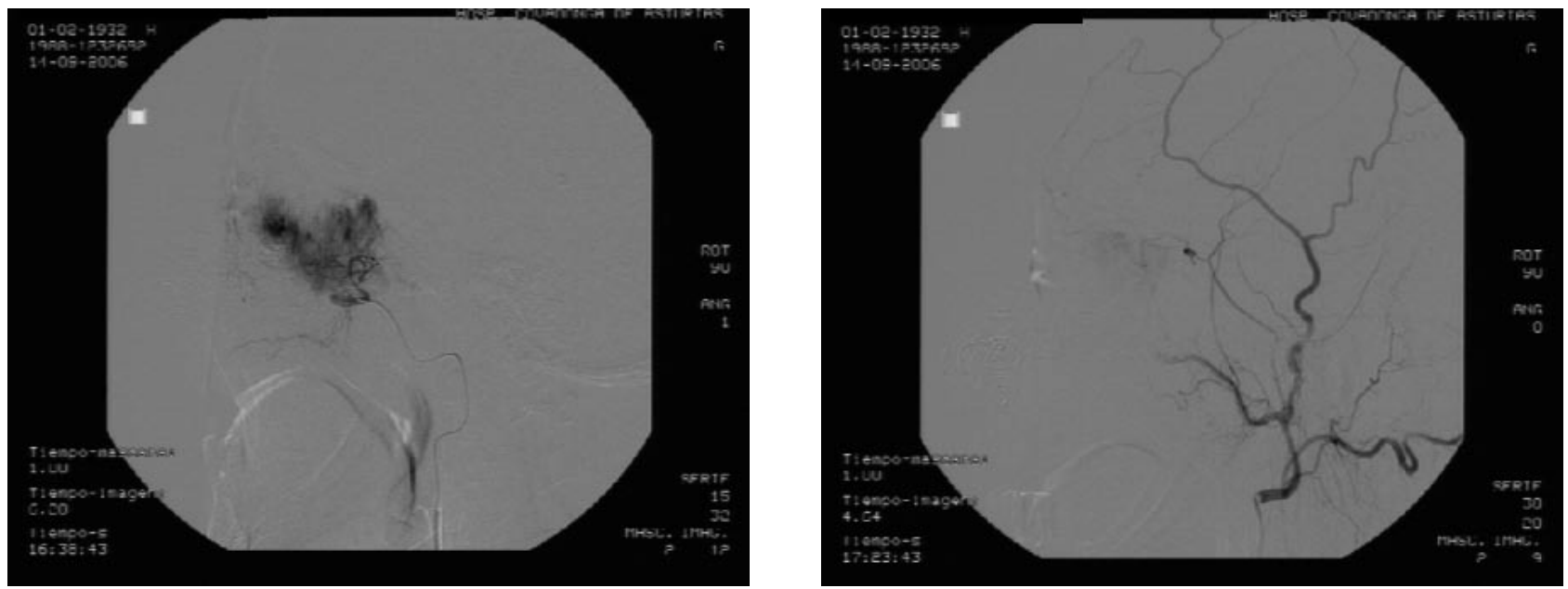

FIGURA 3. Embolización de la arteria maxilar interna derecha.

\section{DISCUSIÓN}

El carcinoma de células renales, supone el $85 \%$ de las neoplasias primarias del riñón (2), y representa aproximadamente el $3 \%$ de las neoplasias del adulto y habitualmente afecta a varones entre los 30 y 60 años (3). El $40 \%$ de los casos se presentan con enfermedad metastática en el momento del diagnóstico. Las zonas más frecuentes de metástasis son el pulmón $(76 \%)$, los ganglios regionales $(66 \%)$, el hueso $(42 \%)$, y el hígado $(41 \%)$, sin embargo, se han documentado afectación metastática en cualquier órgano y lugar del organismo.

Esta estirpe tumoral se caracteriza por una gran variabilidad clínica. La historia natural es muy variable pudiendo presentar metástasis en el momento del diagnóstico, aunque también estas pueden aparecer décadas después del primario $(4,5)$. La presencia de metástasis tardía (> 10 años) ocurre entre el $4,7 \%$ y el $11 \%$ de los casos.

Las metástasis del carcinoma de células renales en la nariz y senos paranasales son raras. Existen menos de 100 casos descritos en la literatura. La afectación metastática de origen renal hacia cabeza y cuello suelen asentar en los senos paranasales, glándula parótida y mandíbula.

Pritchyk y cols (7) consideran que la afectación metastática de cabeza y cuello deben ser evaluadas muy concienzudamente ya que estas pueden llegar a comprometer la vía respiratoria, o suponer importantes sangrados. La supervivencia de estos pacientes está relacionada fundamentalmente con el estadio patológico (8). Por tanto, el carcinoma de células renales debe ser considerado en el diagnóstico diferencial de cualquier lesión creciente en cabeza y cuello.

\section{CONCLUSIONES}

En pacientes con carcinoma de células renales la aparición de lesiones en cabeza y cuello debe hacernos sospechar de procesos metastásicos. En algunos casos, pueden preceder el diagnostico de un tumor renal y simular un primario de cabeza y cuello. La historia natural del carcinoma de células renales es muy variable, pudiendo aparecer metástasis hasta décadas después de ser operado el tumor primario del riñón. En el caso de metástasis solitarias en cabeza y cuello, la exéresis quirúrgica de la misma debe ser realizada de forma paliativa en caso de que no pueda ser curativa.

\section{BIBLIOGRAFIA y LECTURAS \\ RECOMENDADAS (*lectura de interés $y^{* *}$ lectura fundamental)}

**1. Ziari M, Shen S, Amato RJ, The Bs. Metastatic renal cell carcinoma to the nose and ethmoid sinus. Urology 2006; 67 (1): 199.

2. Vreugde S, Duttmann R, Halama A, Deron P. Metastasis of a renal cell carcinoma to the nose ad paranasal sinuses. Acta Otorhinolaryngol Belg 1999; 53 (2): 129-31.

3. Simo R, Sykes AJ, Hargreaves SP, Axon PR, Birzgalis AR, Slevin NJ, Farrington WT. Metastatic renal cell carcinoma to the nose and paranasal sinuses. Head Neck 2000; 2 (7): 722-7.

4. Larrosa F, Aguilar F, Traserra J. Ethmoidal metastasis of renal adenocarcinoma. Acta Otorrinolaringol Es`p 2000; 51 (1): 76-9.

*5. Szymanski M, Szymanska A, Morshed K, Siwiec H. Renal cell carcinoma metastases to nose and paranasal sinuses presenting as recurrent epistaxis. Wiad Lek 2004; 57 (1-2): 94-6. 
*6. Prescher A, Brors D. Metastases to the paranasal sinuses: case report and review of the literature. Laryngorhinootologie 2001; 80 (10): 583-94.

**7. Sabo R, Sela M, Sabo G, Herkovitz P, Feinmesser R. Metastatic hypernephroma to the head and neck: inusual case reports and review of the literature. $\mathrm{J}$ Otolaryngol 2001; 30 (3): 140-4.

8. Koscielny S. The paranasal sinuses as metastatic site of renal cell carcinoma. Laryngorhinootologie 1999; 78 (8): 441-4.

Casos Clínicos

Arch. Esp. Urol. 2010; 63 (2): 150-153

\section{ADENOCARCINOMA VESICAL DE CÉLULAS EN ANILLO DE SELLO: REVISIÓN DE NUESTROS CASOS ENTRE 1990-2009}

\section{Luis A. Busto Martín, Manuel Janeiro País, Juan}

González Dacal, Venancio Chantada Abal y Luis Busto Castañón.

Servicio de Urología. Complejo Hospitalario Universitario de Coruña. La Coruña. España.

Resumen.- OBJETIVOS: Presentar una revisión de los adenocarcinomas primarios de vejiga de células en anillo de sello de nuestro servicio.

\section{CORRESPONDENCIA}

Luis A. Busto Martín

Complejo Hospitalario Universitario de Coruña.

la Coruña. (España)

lbm@urologiabusto.com

Aceptado para publicar: 7 de octubre 2009
MÉTODO/RESULTADO: Revisamos las RTU de vejiga realizadas entre 1990 y 2009 encontrando 9 casos de tumores primarios de vejiga de células en anillo de sello (4 puros y 5 mixtos). 8 eran varones y 1 mujer, con edades comprendidas entre los 39 y los 82 años. Tratamiento definitivo consistió en cistectomía radical con derivación tipo Bricker en cuatro de los pacientes, cistectomía con derivación Mainz II en otro de ellos y paliativo en los cuatro restantes con RTU en tres casos y NPC paliativas en otro. Empleamos quimioterapia adyuvante en 3 casos. Sólo dos de los pacientes estaban vivos en el momento del estudio. La media de supervivencia fue de 327 días para los tumores puros y de 586 para los mixtos.

CONCLUSIÓN: Los adenocarcinomas primarios de vejiga con células en anillo de sello son unos tumores poco frecuentes, con peor pronóstico que los de células transicionales. Es importante que descartemos los posibles orígenes metastásicos (de estómago, próstata, ovario, pulmón) ya que el manejo a seguir será distinto en función de la localización del tumor primario. El tratamiento de elección en los primarios de vejiga es la cistectomía radical, con quimioterapia adyuvante en los casos que sea posible. La supervivencia a 5 años es $<$ al $11 \%$.

Palabras clave: Células en anillo de sello. Adenocarcinoma de vejiga. Tumor vesical.

Summary.- OBJECTIVES: To present a revision on the signet-ring cell bladder adenocarcinomas found in our department.

METHODS/RESULTS: We reviewed all the transurethral resections of the bladder (TURB) performed between 1990 and 2009 finding 9 cases of primary signet ring cell adenocarcinomas ( 4 pure and 5 mixed). Eight were male and one female, with ages between 39 and 82 years. Definitive treatment was radical cystectomy with Bricker's urinary diversion in four patients, cysctectomy with Mainz's II diversion in one patient and palliative management with TURB in three cases and percutaneous nephrostomy in the remaining case. We used adyuvant chemotherapy in three cases. Only two patients were alive at the time of the study. Mean survival was 327 days for pure tumors and 586 for the mixed ones.

CONCLUSIONS: Signet-ring cell primary adenocarcinoma of the bladder is an uncommon type of tumor, with worse prognosis than transitional cell cancer. It is important to discard other possible metastatic origins llike stomach, prostate, lung, or ovaryl because the management will be different. Radical cystectomy is the treatment of choice, with adyuvant chemotherapy if possible. Five year survival is less than $17 \%$.

Keywords: Signet-ring cell. Bladder adenocarcinoma. Bladder tumor. 